\title{
Aspectos e conservação da biodiversidade na Comunidade Quilombola Santa Cruz - Brejo Grande/SE
}

\author{
Aspects and biodiversity conservation in the Quilombola Community Santa Cruz - Brejo \\ Grande / SE
}

\author{
ANDRADE $^{1}$, R. S.; ALVES ${ }^{2}$, N. M. S.; FARIAS ${ }^{1}$, M. C. V.; SANTANA ${ }^{2}$, B. L. P. \\ raybiotanica@gmail.com
}

\section{Resumo}

A biodiversidade não é exclusivamente um produto da natureza, mas tem sido determinada pela construção social e cultural das comunidades tradicionais que ocupam os diversos ambientes da Terra. O estudo objetivou analisar a relação da comunidade quilombola Santa Cruz com a biodiversidade da paisagem onde vive composta pelo mangue e a restinga, com vistas à sua conservação. A metodologia se apoia na análise integrada da paisagem que entende a dinâmica ambiental como resultante da interação entre os componentes físicos, biológicos e sociais. Foram realizadas revisão bibliográfica, relatos orais e trabalhos de campo guiados pelos membros da comunidade Santa Cruz, do município de Brejo Grande. Os resultados permitiram constatar que a comunidade possui um conhecimento apurado sobre os tipos de usos das espécies que compõem o conjunto florístico do mangue e da restinga. Tais conhecimentos refletem a bagagem cultural adquirida através de observações e ensinamentos transmitidos oralmente de geração em geração.

Palavras-chave: biodiversidade, comunidades tradicionais, conservação.

\begin{abstract}
Biodiversity is not exclusively a product of nature, but it has been determined by the social and cultural construction of traditional communities that occupy the various environments of the Earth. The study aimed to analyze the relationship of the quilombola community Santa Cruz with the landscape of biodiversity where you live, composed of mangrove and salt marsh, with a view to their conservation. The methodology is based on the integrated landscape analysis to understand the environmental dynamics as a result of the interaction between the physical, biological and social components. literature review was performed, oral reports and field work guided by members of the Santa Cruz community in the municipality of Brejo Grande. The results demonstrated that the community has an calculated understanding of the types of uses of the species that make up the floristic whole mangrove and sandbank. Such knowledge reflect the cultural baggage acquired through observations and orally transmitted teachings from generation to generation.
\end{abstract}

Keywords: biodiversity , traditional communities , conservation.

\section{INTRODUÇÃO}

O conhecimento humano adquirido ao longo do processo histórico sobre o ambiente tem recebido maior atenção, na atualidade, e permitiu que conceitos anteriormente elaborados passassem por um processo de revisão, especialmente àqueles que envolvem o conhecimento científico dos ecossistemas e da sua biodiversidade associada (FACHIM; GUARIM, 1995). Nesse sentido, entende-se que a diversidade biológica também tem sido determinada pela construção

\footnotetext{
${ }^{1}$ Ray Santos Andrade, Departamento de Biologia, Universidade Federal de Sergipe, São Cristóvão-SE, Brasil

${ }^{2}$ Neise Mare de Souza Alves, Departamento de Geografia, Universidade Federal de Sergipe, São Cristóvão-SE, Brasil

${ }^{3}$ Marta Cristina Vieira Farias, Departamento de Biologia, Universidade Federal de Sergipe, São Cristóvão-SE, Brasil

${ }^{4}$ Bruna Leidiane Pereira Santana, Departamento de Geografia, Universidade Federal de Sergipe, São Cristóvão-SE, Brasil
} 
social e cultural das comunidades tradicionais que ocupam os diversos ambientes da Terra (DIEGUES; ARRUDA, 2001). Os membros desses grupos sociais têm uma relação com o meio ambiente e utilizam em benefício próprio os recursos naturais que se encontram disponíveis naquele local. Assim, com a vivência naquele contexto ambiental, eles passam a desenvolver um conhecimento próprio e a ter uma relação com esses recursos.

De acordo com Barbieri (2010), a noção de biodiversidade ainda é muito imprecisa, mas ela pode ser interpretada como a totalidade dos genes, espécies e ecossistemas que representam a diversidade biológica de uma região.

Em relação à flora, o Brasil é um país com grande riqueza, possuindo mais de 56.000 espécies de vegetais (GIULIETTI et al. 2005). Essa riqueza desperta o interesse de comunidades científicas internacionais, que buscam conhecer melhor as espécies vegetais para conservá-las e utilizá-las racionalmente (SOUZA; FELFILI, 2006).

Albuquerque e Andrade (2002) afirmam que inúmeras comunidades tradicionais possuem sistemas próprios de manejo dos recursos naturais. Essas práticas podem causar menos prejuízos ambientais. Entender a maneira como essas comunidades utilizam os recursos do ambiente pode resultar em benefícios para os ecossistemas.

Portanto, o presente trabalho tem por objetivo analisar a relação da comunidade quilombola Santa Cruz com a biodiversidade da paisagem onde vive, composta pelo mangue e a restinga, com vistas à sua conservação.

\subsection{Localização e caracterização da área de estudo}

Esse estudo foi realizado no povoado e comunidade quilombola Santa Cruz, no município de Brejo Grande, Sergipe.

Brejo Grande é um município costeiro do litoral norte de Sergipe, limitando-se ao norte com o estado de Alagoas; a noroeste com o município de Ilha das Flores; a leste com o rio São Francisco, a oeste e sudoeste com o município de Pacatuba e ao sul com o oceano Atlântico (ALVES, 2010).

O clima da região é caracterizado como do tipo Megatérmico Subúmido/úmido, (SEPLAG/SERGIPE, 2014) podendo apresentar períodos de seca. A temperatura média anual é elevada, de $25,0^{\circ} \mathrm{C}$, e os índices pluviométricos anuais atingem cerca de $1300 \mathrm{~mm}$ (ALVES, 2010).

O município compreende a unidade geomorfológica Planície Costeiro-Deltaica do Rio São Francisco. Essa denominação da planície visa evidenciar sua gênese, ou seja, é formada por sedimentos fluviais submetidos à dinâmica marinha, que formou o delta dominado por ondas na foz do rio referido (ALVES, 2010). 
A Planície Costeiro-Deltaica constitui um espaço de transição entre a Interface Continental e a Interface Marinha (ALVES, 2010). É um ambiente sensível aos processos e fenômenos naturais, condição revelada pelo mosaico de feições morfológicas que a compõe - terraços marinhos e cordões litorâneos, dunas costeiras inativas, planície fluviomarinha e planície fluviolagunar - e às ações antrópicas, evidentes nos problemas ambientais presentes na paisagem.

As dunas costeiras inativas ocupam grande área do município estendendo-se do povoado Brejão dos Negros até a Carapitanga. São formadas por depósitos eólicos litorâneos atuais compostos por areias bem selecionadas, com grãos arredondados. $\mathrm{Na}$ área, os campos dunares são constituídos por dunas parabólicas simples e compostas. A vegetação de restinga apresenta diferentes graus de antropização devido aos tipos de uso das terras, predominando a cocoicultura e a pecuária extensiva (ALVES, 2010).

A planície fluviolagunar em Brejo Grande é formada por sedimentos predominantemente de origem fluvial, formada por depósitos de areia e silte argilosos ricos em matéria orgânica e sujeita a inundações. Nesta feição morfológica é comum a presença de depressões ocupadas por lagoas temporárias e permanentes (ALVES, 2010).

A Planície fluviomarinha está submetida diariamente a oscilação das águas marinhas, pois se encontra no ambiente onde interage a dinâmica do oceano com a dinâmica fluvial. A salinidade das águas favoreceu o desenvolvimento da vegetação de mangue e do ecossistema manguezal. Ela é formada por sedimentos finos e matéria orgânica que constituem um substrato propício para a colonização das espécies vegetais do mangue (ALVES, 2010).

Sobre essas morfologias da Planície Costeiro-Deltaica se desenvolveram os solos de Brejo Grande. Os principais tipos são: Gleissolos Háplicos; Neossolos Quartzarênicos; Neossolos Flúvicos e Solos Indiscriminados de Mangue (BRASIL, 1983). Eles se diferenciam pelas características texturais e influência ou não do lençol freático.

$\mathrm{Na}$ área ocupada pela comunidade Santa Cruz predominam os Neossolos Quartzarênicos e os Solos Indiscriminados de Mangue. Os primeiros se desenvolveram a partir dos sedimentos fluviais e marinhos. São solos pouco evoluídos, apresentam baixa fertilidade natural e são suscetíveis à ação dos processos eólicos. Os últimos são formados por sedimentos de granulometria fina advindos de depósitos fluviais e fluviomarinhos. Apresenta coloração escura, elevado teor de matéria orgânica e sais, estando diariamente ou periodicamente inundados pelas águas marinhas em razão das oscilações das marés. (ALVES, 2010).

As características dos solos influenciam na composição da vegetação. Portanto, sobre os Neossolos Quartzarênicos se encontra a Formação Pioneira com espécies dos ambientes de Áreas 
de Influência Marinha (Restinga) e os Solos Indiscriminados de Mangue estão colonizados pela Formação Pioneira de Influência Fluviomarinha (ALVES, 2010).

A Restinga é representada por espécies herbáceas, arbustivas e arbóreas, distribuídas espacialmente de acordo com a textura dos solos e o teor de salinidade. Na área em análise, os solos são favoráveis para o crescimento de espécies arbustivas e arbóreas associadas às feições de dunas inativas (ALVES, 2010). Apesar de ser um ambiente frágil, esse ecossistema litorâneo tem sofrido perda de sua biodiversidade devido à especulação imobiliária, que valoriza a chamada "vista para o mar", além da agricultura, pecuária extensiva e poluição.

A vegetação de Mangue é composta por espécies vegetais que sobrevivem em condições anaeróbicas. As espécies normalmente encontradas nesse conjunto florístico são as arbóreas, das quais se destacam o mangue bravo ou vermelho (Rhizophora mangle) e do mangue manso ou branco (Laguncularia racemosa) que possuem características morfológicas adaptadas a meios estressantes. A vegetação de mangue e o substrato lamoso propiciam a instalação do ecossistema manguezal, reconhecido como o berçário, local de reprodução e abrigo de espécies aquáticas do ambiente fluvial e marinho.

\section{METODOLOGIA}

O desenvolvimento deste estudo está fundamentado nos princípios sistêmicos representados no modelo teórico-metodológico Geossistêmico, que entende a paisagem como resultado de um conjunto de fatores naturais (solo, clima, vegetação, geomorfologia, geologia, hidrografia) que interagem entre si, simultaneamente, e integra a ação humana. Desse modo, é definida a dinâmica ambiental. Assim, a análise foi conduzida principalmente com base em Bertrand (1972).

Os procedimentos utilizados nos estudos foram pautados na pesquisa bibliográfica, leitura de artigos científicos e dissertações de obras que tratam sobre as temáticas. Além disso, considerando a abordagem qualitativa, foram obtidos depoimentos orais junto aos membros da comunidade quilombola Santa Cruz, fonte importante de pesquisa, tomando por base as suas experiências e práticas na relação com os recursos ambientais onde vivem.

Os trabalhos de campo permitiram a observação das características da vegetação da área restinga e mangue - e da sua biodiversidade, aspectos da ocupação das terras e interação com os membros da Comunidade Santa Cruz. Para Silvestre e Moreira (2011), as atividades de campo são importantes para a obtenção de informações acerca do objeto de estudo do pesquisador.

\section{RESULTADOS E DISCUSSÃO}


Os grupos humanos sempre extraíram da natureza os recursos necessários ao atendimento de suas necessidades básicas. De acordo com Almeida e Albuquerque (2002) o uso da flora como alimento, no tratamento de enfermidades ou como fonte de energia sempre esteve presente na história do homem, muito antes dele se tornar agente produtor de culturas, para garantir a sua sobrevivência.

As 50 famílias que compõem a comunidade quilombola Santa Cruz ocupam uma área no município de Brejo Grande situada entre o mangue e a restinga. Esta condição contribuiu para que, naturalmente, passassem a utilizar as plantas da região de várias maneiras, em particular, como medicamento e alimento. Essa comunidade extrai os recursos vegetais através de um sistema de manejo próprio. Na vivência diária, há sempre uma preocupação com os recursos da natureza e muitos moradores da comunidade citam a participação do IBAMA (Instituto Brasileiro de Meio Ambiente e dos Recursos Naturais Renováveis) na fiscalização ambiental para a conservação dos ecossistemas restinga e manguezal.

Em seus estudos sobre análise geoambiental e socioeconômica dos municípios costeiros do litoral norte do estado de Sergipe, Alves (2010) constatou que essa região vem sofrendo forte pressão antrópica, e a vegetação é o elemento que apresenta maior impacto pela ação humana, em razão do desmatamento para a implantação de atividades agrícolas - cultivo de coco-da-bahia (Cocos nucifera) e carcinicultura - e extrativismo da madeira na restinga no manguezal para a produção de lenha. Esses processos têm sido responsáveis pela perda da biodiversidade.

De acordo com os moradores da comunidade quilombola Santa Cruz, o conhecimento sobre o uso das plantas é passado para os jovens pelos pais ou avós. Segundo Diegues e Arruda (2001), as populações tradicionais que convivem com a biodiversidade de espécies vivas, costumam nomeálas e classificá-las segundo suas próprias categorias, sendo esse conjunto de saberes e saber-fazer, transmitido de geração para geração.

As atividades produtivas desenvolvidas pelos membros dessa comunidade - pesca, cata de caranguejo e de mariscos, entre outras - costumam estar entremeadas no mesmo espaço e se relacionam com os conjuntos florísticos da vegetação original de restinga e mangue.

$\mathrm{Na}$ restinga, dentre as espécies mais utilizadas pela comunidade, destacam-se a amescla (Protium heptaphyllum), sambacaitá (Mesosphaerum pectinatum), mama de cachorra (Eugenia brejoensis), ubaia (Eugenia pyriformis), o cambuí (Myrciaria floribunda) e o jatobá (Hymenaea courbaril). Cada uma dessas espécies vegetais tem usos específicos e importância significativa para aqueles que usufruem dos seus benefícios, seja no tratamento de enfermidades, na alimentação e uso tecnológico (construção de casas de taipa e confecção e tingimento de redes). 
Na vegetação de mangue também são encontradas espécies com potencial econômico como o mangue-vermelho ou bravo (Rhizophora mangle) e o mangue-branco ou manso (Laguncularia racemosa). A comunidade costuma utilizar o tanino, substância extraída da casca da Rhizophora mangle para obtenção da tinta usada no tingimento da rede de pesca chamada de camboa, a fim de camufla-la no ambiente do manguezal. Essas redes são fixadas, com estacas de madeira da própria vegetação, na desembocadura dos canais de maré da planície fluviomarinha no período da preamar, para que os peixes fiquem retidos no período da maré vazante. A Laguncularia racemosa é utilizada para construir estacas, cercas e o entrelaçamento de madeiras das casas de taipa. Na atualidade, essa prática tem sido reduzida, em razão da construção de casas de alvenaria, diminuindo o uso dessa espécie e, consequentemente, favorecendo a conservação do ecossistema manguezal.

Cabe destacar que as práticas de exploração sustentável dos recursos vegetais não causam impactos significativos aos ecossistemas que compõem a paisagem local. Isso tem contribuído para a conservação da diversidade biológica da restinga e do mangue pela comunidade Santa Cruz, que reconhece os benefícios que podem obter com as espécies desses ecossistemas.

Os membros da comunidade quilombola conhecem o uso medicinal da amescla, do jatobá e da sambacaitá no tratamento de enfermidades. Esses vegetais são retirados da restinga pela comunidade e os remédios preparados atendem as suas necessidades básicas. Cunha e Bortolotto (2011) afirmam que os remédios caseiros produzidos com os recursos vegetais exercem um papel importante na vida das comunidades rurais de baixo poder aquisitivo. Da mesma forma, esse princípio se aplica às comunidades tradicionais costeiras e ribeirinhas, como a comunidade Santa Cruz.

Na comunidade em análise, se costuma extrair a resina da casca da amescla, que é colocada em uma panela e queimada com noz-moscada. O vapor exalado, chamado localmente de defumador, é utilizado para descongestionar as vias respiratórias ou combater tonturas. De acordo com Maria, moradora da comunidade quilombola povoado Santa Cruz: "A resina da amescla é bom pra remédio, o defumador é bom pra curar catarro no peito".

Por sua vez, as folhas secas e maceradas da sambacaitá podem ser utilizadas no preparo de chás para curar inflamações ou no preparo de cataplasma, que é colocado diretamente sobre os ferimentos, em razão da sua propriedade cicatrizante. No seu depoimento, Dona Edileuza afirma que: "O sambacaitá é bom pra colocar na ferida, ajuda na cicatrização. Coloca o pó da folha em cima da ferida. O chá é bom pra inflamação em qualquer canto".

No que diz respeito ao jatobá, os moradores mais experientes afirmam que o lambedor, ou seja, um tipo de xarope caseiro preparado com a casca dessa planta é empregado para minimizar o 
“problema de nervos". Em seus estudos, Rozemberg (1994) associou problema de "nervos" com uma síndrome de caráter cultural associada aos distúrbios psíquicos, como ansiedade, nervosismo, depressão, entre outros. Segundo um membro do povoado Santa Cruz, de codinome Seu Cabo Véio “Antigamente as pessoas sabiam que o jatobá servia pra problema de nervo. É bom também pra lambedor, pra curar gripe".

Desse modo, pode-se inferir que os membros da comunidade Santa Cruz identificam no jatobá propriedades calmantes ou energizantes para o organismo.

A comunidade ressalta ainda que na restinga há uma variedade de frutos bastante apreciados e de interesse econômico, entre os quais se destacam a ubaia (Eugenia pyriformis), a mama de cachorro (E. brejoensis) e o cambuí (Myrciaria floribunda), representantes da família Myrtaceae.

0s frutos do cambuí e da mama de cachorro são consumidos diretamente quando maduros, durante as caminhadas na área de mata da restinga. 0s sucos e licores do cambuí fazem parte da culinária local. A ubaia é utilizada na produção de sucos, geladinhos e sorvetes. Os produtos derivados dessas espécies alimentícias representam fonte de renda complementar para as famílias da comunidade, principalmente para as mulheres, que os comercializam em feiras livres e/ou nas próprias residências. A senhora Maria Josinete, conhecida localmente por Comadre, destaca que - “A ubaia tem o fruto amarelo. Ela é azeda, mas faz suco, geladinho e sorvete. Aqui na comunidade vende, mas tem a época”.

Na área do povoado Santa Cruz, o conhecimento sobre as espécies vegetais pelos membros da comunidade quilombola e o reconhecimento de sua importância, em razão do uso ou benefícios que elas proporcionam, contribuem para a conservação da biodiversidade. 0 uso sustentável dos recursos e o envolvimento dessa comunidade em práticas conservacionistas são formas viáveis de preservar o que ainda resta da vegetação nativa e isso depende, principalmente, do nível de conscientização dos moradores e não apenas dos órgãos responsáveis pela fiscalização ambiental para a conservação da diversidade biológica local. 


\section{CONSIDERAÇÕES FINAIS}

A metodologia adotada se mostrou adequada para os objetivos do estudo realizado. Os resultados demostram a importância da restinga e do mangue para os moradores da Comunidade Santa Cruz, uma comunidade tradicional quilombola que conhece e utiliza as espécies vegetais da região, principalmente como medicamento, alimento, na confecção de objetos e mesmo na construção. Isso demonstra que a comunidade preserva o conhecimento adquirido ao longo das gerações e os repassa para os mais jovens.

Foi possível constatar que a comunidade no dia a dia tem uma íntima relação com a flora local, especialmente, com as espécies destacadas na presente análise. Apesar dos moradores adotarem um manejo simples para a retirada de partes das plantas, é importante que eles conheçam metodologias de coleta sustentável que possam permitir a conservação da biodiversidade dos ecossistemas restinga e manguezal. Desse modo, são indispensáveis estudos mais apurados sobre os ecossistemas locais, a fim de que os órgãos ambientais possam ter uma participação efetiva nessa ação.

\section{REFERÊNCIAS}

ALBUQUERQUE, U.P.; ANDRADE, L.H.C. Conhecimento botânico tradicional e conservação em uma área de caatinga no Estado de Pernambuco, Nordeste do Brasil. Acta Botanica Brasilica, v. 16, n. 3, p. 273-285, 2002.

ALMEIDA, C. F. C. B. R.; ALBUQUERQUE, U.P. Uso e conservação de plantas e animais medicinais no Estado de Pernambuco (Nordeste do Brasil): um estudo de caso. Interciência, v. 27 n. 6 , p. 276-285, 2002.

ALVES, N.M.S. Análise geoambiental e socioeconômica dos municípios costeiros do litoral norte do estado de Sergipe - Diagnóstico como subsídio ao ordenamento e gestão do território. Tese (Doutorado em Geografia) Núcleo de Pós-Graduação em Geografia, Pró-Reitoria de PósGraduação e Pesquisa, Universidade Federal de Sergipe, 2010.

BARBIERI, E. Biodiversidade: a variedade de vida no planeta Terra. In: Instituto de Pesca, Agência Paulista de Tecnologia dos Agronegócios, Secretaria de Agricultura e Abastecimento do Estado de São Paulo. 2010, 16 p.

BERTRAND, G. Paisagem e geografia física global: esboço metodológico. Tradução Olga Cruz - Caderno de Ciências da Terra. Instituto de Geografia da Universidade de São Paulo, nº13, 1972.

BRASIL. Ministério das Minas e Energia. Projeto RADAMBRASIL: folha SC.24/25 Aracaju/Recife: geologia, geomorfologia, pedologia, vegetação, uso potencial da terra. Rio de Janeiro, 1983. 851 p. (Levantamento de Recursos Naturais, 30). 
CUNHA, S.A.C.; BORTOLOTTO, I. M. Etnobotânica de plantas medicinais no assentamento Monjolinho, município de Anastácio, Mato Grosso do Sul, Brasil. Acta Botanica Brasilica, v.25, n. 3, p. 685-698, 2011.

DIEGUES A. C.; ARRUDA R. S. V. (Orgs.). Saberes tradicionais e biodiversidade no Brasil. Brasília: Ministério do Meio Ambiente, 2001.

FACHIM, E.; GUARIM, V. L. M. S. Conservação da biodiversidade: espécies da flora de Mato Grosso. Acta Botanica Brasilica, v. 9, n. 2, p. 281-287, 1995.

GIULIETTI, A.M., HARLEY, R.M., QUEIROZ, L.P., WANDERLEY, M.G.L.; VAN DEN BERG, C. Biodiversidade e conservação das plantas no Brasil. Megadiversidade v. 1, n. 1, p. 52-61, 2005.

ROZEMBERG, B. O consumo de calmantes e o" problema de nervos" entre lavradores. Revista de saúde pública, v. 28, n. 4, p. 300-308, 1994.

SEPLAG/SERGIPE. Enciclopédia dos municípios Sergipanos. Aracaju: Secretaria de Estado do Planejamento, Orçamento e Gestão. p. 509, 2014.

SILVESTRE D. O.; MOREIRA A. P. C. Uso, vivência e conservação do meio ambiente em populações tradicionais: o caso da comunidade quilombola de Caiana dos Crioulos, Alagoa Grande (PB). Cadernos do Logepa, v. 6 n. 2), p. 180-202, 2011

SOUZA, C. D.; FELFILI, J.M. Uso de plantas medicinais na região de Alto Paraíso de Goiás, GO, Brasil. Acta Botanica Brasilica, v. 20, n. 1, p. 135-142, 2006.

\section{AGRADECIMENTOS}

Estes estudos foram desenvolvidos com bolsa remunerada PIBIX, apoio financeiro da Pró-Reitoria de Extensão, da Universidade Federal de Sergipe.

Recebido em: 14/08/2016

Aceito para publicação em: 01/10/2016 